\title{
Expression of Telomerase Catalytic Subunit (hTERT) mRNA Does Not Predict Survival in Patients with Transitional Cell Carcinoma of the Upper Urinary Tract
}

\author{
Kuniaki Nakanishi, M.D., Sadayuki Hiroi, M.T., Toshiaki Kawai, M.D., Shinsuke Aida, M.D., \\ Hiroyasu Kasamatsu, M.T., Takashi Aurues, M.D., Tomosumi Ikeda, M.D. \\ Division of Environmental Medicine (KN, TA, TI), National Defense Medical College Research Institute; \\ and Departments of Pathology (SH, TK) and Laboratory Medicine (SA) and Central Research Laboratory \\ (HK), National Defense Medical College, Tokorozawa, Japan
}

Telomerase is a ribonucleoprotein enzyme that synthesizes telomeric repeats onto chromosomal ends using a segment of its RNA component as a template. Its activity has become an established indicator of the diagnosis, biological behavior, and prognosis of several tumors. However, few studies have investigated the diagnostic and prognostic importance of the expression of telomerase catalytic subunit (hTERT) mRNA in transitional cell carcinoma of the upper urinary tract (TCC-UUT). We investigated the expression of hTERT mRNA using in situ hybridization in 125 cases of TCC-UUT, and also its relation with the expression of telomerase RNA component (hTERC), proliferating cell nuclear antigen (PCNA) immunoreactivity, clinicopathologic parameters, and clinical outcome. A positive expression of hTERT mRNA was recognized in $93.6 \%$ of the samples and was apparent within the cytoplasm of tumor cells. In the normal urothelium examined in a few cases, its expression was barely detected. hTERT mRNA scores showed a significant association with hTERC score. However, no relationship was found between the expression of hTERT mRNA and clinicopathologic findings, PCNA index, or prognosis. These results suggest that the expression of hTERT mRNA does not predict prognosis in TCC-UUT.

KEY WORDS: Telomerase catalytic subunit (hTERT), Transitional cell carcinoma, Upper urinary tract.

Mod Pathol 2001;14(11):1073-1078

Copyright $\odot 2001$ by The United States and Canadian Academy of Pathology, Inc.

VOL. 14, NO. 11, P. 1073, 2001 Printed in the U.S.A.

Date of acceptance: July 21, 2001.

Address reprint requests to: Kuniaki Nakanishi, M.D., Division of Environmental Medicine, National Defense Medical College Research Institute, Tokorozawa 359-8513, Japan; e-mail: nknsknak@res.ndmc.ac.jp; fax: 81-42-991-1612.
Telomerase is a ribonucleoprotein enzyme that synthesizes telomeric DNA at the end of chromosomes and compensates for the end-replication problem, allowing cells to proliferate indefinitely (1, $2)$. Recent studies using the polymerase chain reaction (PCR)-based telomerase repeat amplification protocol (TRAP) assay have shown that telomerase is activated in most human cancer tissues, but not in most normal tissues or in tissues adjacent to malignant or benign tumors $(3,4,5)$. Further, high levels of telomerase activity have been found to be associated with an unfavorable prognosis in neuroblastomas (4) and gastric carcinomas (5). This being so, it seemed possible that telomerase activity would be a useful marker for cancer detection and prognosis.

Recently, three major subunits of human telomerase-namely, telomerase-associated protein (TEP1), human telomerase RNA (hTERC), and human telomerase catalytic subunit (hTERT)- have been identified. Of these, TEP1, the human homolog of the telomerase p80 found in the protozoan tetrahymena, is expressed ubiquitously, and does not correlate with levels of telomerase activity (6). hTERC is cloned as the template RNA for telomerase, and although hTERC is predominantly seen in cancer tissues, the expression levels of hTERC obtained using Northern blot analysis and/or in situ hybridization may not always parallel telomerase activity $(7,8)$. hTERT contains the reverse transcriptase that catalyzes this reaction, and recent studies have demonstrated (1) that hTERC and hTERT form the minimum complex needed for telomerase activity and that (2) that introduction of the gene encoding hTERT into telomerase-negative human cells leads to the activation of telomerase (6, 9). Furthermore, Blasco et al. has found a close correlation between telomerase activity and hTERT expression (9). Consequently, up-regulation of 
hTERT expression is thought to play an important role in human carcinogenesis.

Although several studies have investigated telomerase activity in TCC of the urinary bladder (10-19), no studies have investigated either the diagnostic or the prognostic importance of hTERT expression in transitional cell carcinoma of the upper urinary tract (TCC-UUT). Consequently, the current study, using an in situ hybridization approach to examine formalin-fixed, paraffin-embedded, tumor-tissue sections from 125 patients with TCC-UUT, was aimed at ascertaining (1) whether hTERT mRNA is expressed in such sections, (2) whether its expression is correlated with the expression of hTERC, and (3) whether its expression is correlated with various clinicopathologic findings, with proliferating cell nuclear antigen (PCNA) immunoreactivity, and/or with clinical outcome in TCC-UUT patients.

\section{MATERIALS AND METHODS}

The material used comprised one hundred twenty-five surgically resected specimens from patients with primary transitional cell carcinoma of the upper urinary tract which had been obtained at the Mutual Aid Associations' Hospital, Tachikawa, Japan, and National Defense Medical College Hospital, Tokorozawa, Japan between 1970 and 1995. Their histopathologic stage was determined according to the criteria proposed by the International Union Against Cancer (UICC; 20). Tumor cells were divided histopathologically into two grades using the criteria for urinary bladder tumors described in the Third Series Fascicle, Armed Forces Institute of Pathology (AFIP; 21).

In situ hybridization was performed essentially as previously described (22). Briefly, sections were treated with $0.2 \mathrm{~N} \mathrm{HCl}$ for $20 \mathrm{~min}$, then incubated in $2 \times$ SSC for $10 \mathrm{~min}$ at $37^{\circ} \mathrm{C}$, and incubated in 5 $\mu \mathrm{g} / \mathrm{mL}$ proteinase $\mathrm{k}$ for $10 \mathrm{~min}$ at $37^{\circ} \mathrm{C}$. Sections were subsequently postfixed in $4 \%$ paraformaldehyde for $5 \mathrm{~min}$, then incubated in $0.1 \mathrm{~mol} / \mathrm{l}$ triethanolamine buffer, $\mathrm{pH} 8.0$, containing $0.25 \%$ (vol/ vol) acetic anhydride for $10 \mathrm{~min}$ to prevent nonspecific binding due to oxidation of the tissue. Hybridization was carried out overnight at $42^{\circ} \mathrm{C}$ in $50 \%$ (vol/vol) deionized formamide, $5 \times$ Denhardt's solution, $5 \%$ (wt/vol) dextran sulfate, $2 \times$ SSC, 0.3 $\mathrm{mg} / \mathrm{mL}$ salmon sperm DNA, $5 \mathrm{~mm}$ EDTA, and 10 $\mathrm{ng} / \mathrm{mL}$ digoxigenin-labeled probes. After performing a final stringent wash at $55^{\circ} \mathrm{C}$ for $20 \mathrm{~min}$, hybridization was detected immunologically. The antisense digoxigenin-labeled probe was $194 \mathrm{bp}$ of human telomerase cDNA inserted at the SmaI site of pBluescript II KS $( \pm$ ) (a kind gift from SRL, Tokyo, Japan) under a T7 promoter, and the corresponding sense probe was $194 \mathrm{bp}$ of hTERT cDNA placed under a T3 promoter using an RNA-labeling kit (Boehringer Mannheim, Mannheim, Germany). Lung carcinomas with telomerase activity served as a positive control. The corresponding sense probe was used to provide a negative control. The intensity and extent of staining were each scored from 0 to 3 , with 0 representing no staining. The intensity was scored as 1, indicating weak, 2, moderate; or 3, strong staining (Fig. 1). The extent of staining was scored as 1, indicating 10 to $33 \%$ of tumor area stained; 2, 34 to $66 \%$ stained; or 3 , $\geq 67 \%$ stained. These two scores were summed to give in each case a final score (ranging from 0 to 6 ) for use in the statistical analysis. The evaluation was performed by a investigator (NK) blind to the tumor stage and grade.

The hTERC expression was evaluated using in situ hybridization; the technique used and the results obtained in these same patients have been reported elsewhere (22).

For the analysis of PCNA, and on the basis of the immunoreaction in at least 1000 tumor cells, the percentage of nuclei with a positive immunoreaction (PCNA index) was determined as previously described (22). The PCNA index was classified as high if it was $\geq 69 \%$, a figure representing the median value for the carcinomas.

For statistical analysis, disease-free and overall survival rates were the two main dependent variables tested in this study. Disease-free survival was defined as the period between the initial radical operation and the subsequent appearance of recurrence or metastasis. Recurrence was defined as TCC occurring anywhere in the genitourinary tract. The end-point was either recurrence/metastasis of TCC or the closing date of the study, whichever came first. "Overall survival" was defined as the interval between surgery and death; the end-point for this variable was either death or the closing date of the study.

Disease-free and overall survival curves for all of the univariate analyses were assessed using the Kaplan-Meier method. Comparisons between two or more survival curves were assessed using Wilcoxon and log-rank tests. Multivariate analysis of the clinicopathologic parameters was performed using the Cox stepwise-regression model. The above analyses were performed using the SAS statistical software package (SAS Institute, Inc., Cary, NC; 23). The comparisons in respect of stage were performed using Mann-Whitney's $U$ test. Comparisons in respect of age, sex, grade, pattern of growth, and proliferating nuclear cell antigen were performed using the Chi-square analysis. Regression analysis of the final scores for hTERT and hTERC mRNA expressions was performed using Spearman's correlation coefficient by rank. 

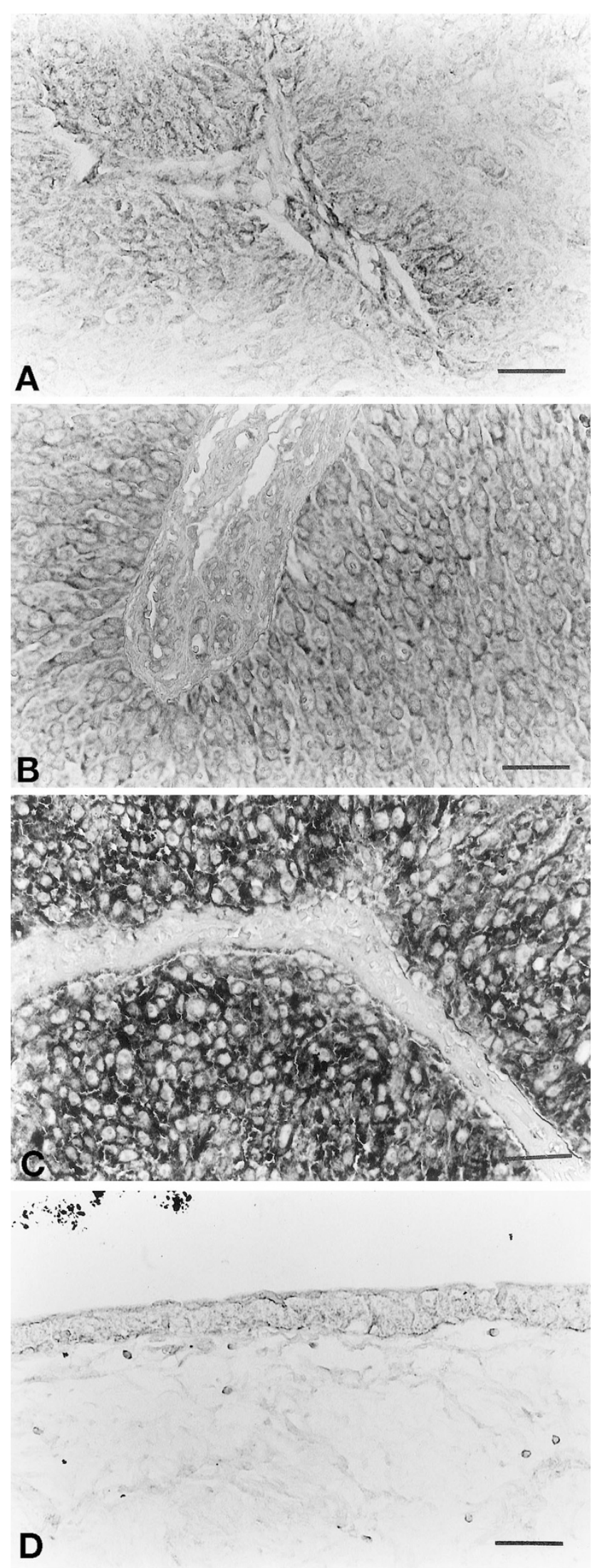

FIGURE 1. In situ hybridization for (hTERT) in transitional cell carcinoma of the upper urinary tract. The signal for hTERT was seen frequently within the cytoplasm of tumor cells. Its expression varied from weak to strong (A: weak; B: moderate; C: strong). In the normal urothelium of a few cases, its expression was barely detected (D). Scale bars: A, B, C, and $\mathbf{D}, 100 \mu \mathrm{m}$.

\section{RESULTS}

The patients' age at diagnosis ranged within 34 to 83 years, with a median age of 67 years. Thirty-one of the 125 patients died as a result of their tumors 1 to 132 months after surgery (mean, 23 mo; median, $14 \mathrm{mo}$ ). At the time of the study, the remainder had survived 0 to 257 months after surgery (mean, 68 mo; median $61 \mathrm{mo}$ ). Among the 125 cases, 50 tumors $(40.0 \%)$ were in the renal pelvis or calyces, 52 $(41.6 \%)$ were in the ureter, and $23(18.4 \%)$ were multicentric. Ten patients had simultaneous bladder tumors at the time of diagnosis, 30 had subsequent bladder tumors, and 6 had an antecedent bladder tumor. In all, $42(33.3 \%)$ patients had an associated bladder neoplasm; of these, 4 had such a neoplasm at more than one of the above times and thus appear in more than one group. The initial management of the 121 patients who were not treated as having bladder cancer included complete nephroureterectomy with a bladder cuff (89 patients), nephroureterectomy without a bladder cuff (8 patients), nephroureterectomy with total cystectomy (9 patients), nephrectomy (13 patients), and urectomy ( 2 patients). Thirty-two patients received adjacent chemotherapy (21 patients), radiotherapy (7 patients), or both (4 patients), in addition to surgery.

The tumors were divided into three groups (A, B, and $\mathrm{C}$ ) on the basis of tumor stage. There were 48 cases $(38.4 \%)$ in Group A (papillary, non-invasive tumors, pTa), 19 cases (15.2\%) in Group B (tumors invading the submucosa or muscularis, pT1 and pT2), and 58 cases (46.4\%) in Group C (tumors invading beyond the muscularis or renal parenchyma, or metastasizing the regional lymph node or a distant site, pT3 and pT4).

Among all the patients, twelve of the 48 with a papillary, noninvasive tumor (pTa) showed recurrence ( 8 patients), metastasis ( 1 patient), or both (3 patients), but 36 developed neither recurrence nor metastasis within the follow-up period. The mean follow-up for patients with a noninvasive tumor who had a recurrence and/or metastasis was 64 months (median, 48; range, 14 to 124 ), whereas the mean follow-up for those without recurrence and metastasis was 79 months (median, 82; range, 4 to 203). Of the 77 patients with an invasive tumor (pT1, pT2, pT3, or pT4), 6 had metastasis at surgery or the tumor could not be excised totally by surgery, 36 showed recurrence (8 patients), metastasis (16 patients), or both (12 patients), but the remaining 35 developed neither recurrence nor metastasis within the follow-up period. The mean follow-up for patients with an invasive tumor who showed recurrence and/or metastasis was 36 months (median, 15; range, 1 to 174), whereas the mean 
follow-up for those without recurrence or metastasis was 58 months (median, 34; range, 0 to 257).

A positive hTERT expression was recognized in $93.6 \%$ of the patients (8 cases showed no staining by in situ hybridization). The expression of hTERT was confined to the cytoplasm of tumor cells and was shown frequently in all cell layers (Fig. 1). However, its expression varied from weak to strong. In the normal urothelium examined in a few cases, hTERT expression was barely detected. hTERT scores were significantly correlated with hTERC scores when Spearman's correlation coefficient by rank was employed $(r=0.50, P<.0001)$. In the assessment of the relationship between hTERT expression and clinicopathologic findings, hTERT scores were classified as "high score" if the score was $\geq 5$ because 4 was the median value for the carcinomas studied. No relationship between hTERT score and either clinicopathologic findings or PCNA index was seen (Table 1). Even when the hTERT scores were assessed separately for noninvasive and invasive tumors, no correlation was found between hTERT score and either clinicopathologic findings or PCNA index (Table 1).

The rates for a 5-year disease-free survival and a 5 -year overall survival were $60.9 \%$ and $71.8 \%$, respectively. In the assessment of disease-free survival, 119 patients who had no metastasis at surgery and in whom the malignant tumor was excised totally by surgery were included in the analysis. In the assessment of overall survival, 125 patients were included in the analysis. Univariate analyses of disease-free and overall survivals in all patients revealed that stage, grade, pattern of growth, and PCNA index all had a significant effect on each of the two survival rates in all tumors (Table 2). Next, in the final models of the multivariate analysis, only stage was shown to be a prognostic factor for disease-free and overall survivals: for disease-free survival, the risk ratio was $4.10, P<.0001$; for overall survival, it was $4.65, P<.0001$.

\section{DISCUSSION}

The purpose of our investigation was to look for a possible relationship between hTERT expression and hTERC expression, clinicopathologic findings, or clinical outcome in TCC-UUT. Moreover, correlation of hTERT expression with the PCNA index was to be tested, as was its prognostic significance. We did not observe a positive relationship between hTERT expression and either clinicopathologic findings or PCNA index, although the correlation between hTERT scores and hTERC scores was seen to be significant. Thus, the detection of hTERT does not help predict the prognosis of TCC-UUT.

In the present study, hTERT expression was present in $93.6 \%$ of TCC-UUT patients, whereas it

TABLE 1. Relationship between hTERT Expression ${ }^{\dagger}$ and Clinicopathologic Findings in 125 Cases

\begin{tabular}{|c|c|c|c|c|c|c|c|c|c|c|c|c|}
\hline \multirow{3}{*}{ Correlative Data } & \multicolumn{4}{|c|}{ All tumors $(n=125)$} & \multicolumn{4}{|c|}{ Noninvasive Tumors $(n=48)$} & \multicolumn{4}{|c|}{ Invasive Tumors $(n=77)$} \\
\hline & \multirow{2}{*}{$\begin{array}{c}\text { No. } \\
\text { of } \\
\text { Cases }\end{array}$} & \multicolumn{2}{|c|}{ Expression of hTERT } & \multirow{2}{*}{$P$ Value } & \multirow{2}{*}{$\begin{array}{c}\text { No. } \\
\text { of } \\
\text { Cases }\end{array}$} & \multicolumn{2}{|c|}{ Expression of hTERT } & \multirow{2}{*}{$P$ Value } & \multirow{2}{*}{$\begin{array}{c}\text { No. } \\
\text { of } \\
\text { Cases }\end{array}$} & \multicolumn{2}{|c|}{ Expression of hTERT } & \multirow{2}{*}{$P$ Value } \\
\hline & & High Score & Low Score & & & High Score & Low Score & & & High Score & Low Score & \\
\hline \multicolumn{13}{|l|}{ Age (y) } \\
\hline$\leq 67$ & 64 & 19 & 45 & $0.98^{\ddagger}$ & 25 & 11 & 14 & $0.33^{\ddagger}$ & 39 & 8 & 31 & $0.39^{\ddagger}$ \\
\hline$>67$ & 61 & 18 & 43 & & 23 & 7 & 16 & & 38 & 11 & 27 & \\
\hline \multicolumn{13}{|l|}{ Sex } \\
\hline Male & 89 & 30 & 59 & $0.11^{\ddagger}$ & 37 & 15 & 22 & $0.42^{\ddagger}$ & 52 & 15 & 37 & $0.22^{\ddagger}$ \\
\hline Female & 36 & 7 & 29 & & 11 & 3 & 8 & & 25 & 4 & 21 & \\
\hline \multicolumn{13}{|l|}{ Stage* } \\
\hline Group A & 48 & 18 & 30 & $0.12^{\text {㧊 }}$ & 48 & 18 & 30 & & & & & \\
\hline Group B & 19 & 6 & 13 & & & & & & 19 & 6 & 13 & $0.42^{\ddagger \ddagger}$ \\
\hline Group C & 58 & 13 & 45 & & & & & & 58 & 13 & 45 & \\
\hline \multicolumn{13}{|l|}{ Grade } \\
\hline Low & 74 & 21 & 53 & $0.71^{\ddagger}$ & 42 & 14 & 28 & $0.11^{\ddagger}$ & 32 & 7 & 25 & $0.63^{\ddagger}$ \\
\hline High & 51 & 16 & 35 & & 6 & 4 & 2 & & 45 & 12 & 33 & \\
\hline \multicolumn{13}{|l|}{ Pattern of growth } \\
\hline Papillary & 87 & 28 & 59 & $0.33^{\ddagger}$ & 48 & 18 & 30 & & 39 & 10 & 29 & $0.84^{\ddagger}$ \\
\hline Nonpapillary & 38 & 9 & 29 & & & & & & 38 & 9 & 29 & \\
\hline \multicolumn{13}{|l|}{ PCNA index } \\
\hline$<69 \%$ & 62 & 21 & 41 & $0.29^{\ddagger}$ & 30 & 12 & 18 & $0.64^{\ddagger}$ & 32 & 9 & 23 & $0.55^{\ddagger}$ \\
\hline$\geq 69 \%$ & 63 & 16 & 47 & & 18 & 6 & 12 & & 45 & 10 & 35 & \\
\hline
\end{tabular}

PCNA, proliferating cell nuclear antigen index

${ }^{\dagger}$ hTERT scores were classified as "high score" if the score was $\geq 5$ because 4 was the median value for the carcinomas studied. The extent of staining was scored as 1 , indicating $10-33 \%$ of tumor area stained; $2,34-66 \%$ stained; or $3,>67 \%$ stained. Intensity of staining was scored as 1 , indicating weak; 2 , moderate; or 3 , strong. These two scores were summed to give in each case a final score (ranging from 0 to 6 ).

* The tumors were divided into three groups: Group A (papillary, noninvasive tumors, pTa); Group B (tumors invading the submucosa or muscularis, pT1 and pT2); and Group C (tumors invading beyond the muscularis or renal parenchyma or metastasizing the regional lymph node or a distant site, pT3 and pT4).

‡ Comparisons with respect to age, sex, grade, pattern of growth, and proliferating nuclear cell antigen were performed using the chi-square analysis

\# Comparisons with respect to stage were performed using Mann-Whitney $U$ test. 


\begin{tabular}{|c|c|c|c|c|c|c|c|c|c|c|c|c|}
\hline \multirow{3}{*}{$\begin{array}{l}\text { Prognostic } \\
\text { Indicator }\end{array}$} & \multicolumn{4}{|c|}{ All Tumors } & \multicolumn{4}{|c|}{ Noninvasive Tumors } & \multicolumn{4}{|c|}{ Invasive Tumors } \\
\hline & \multicolumn{2}{|c|}{$\begin{array}{l}\text { Overall Survival } \\
\qquad(n=125)\end{array}$} & \multicolumn{2}{|c|}{$\begin{array}{c}\text { Disease-Free } \\
\text { Survival }(n=19)\end{array}$} & \multicolumn{2}{|c|}{$\begin{array}{l}\text { Overall Survival } \\
\quad(n=48)\end{array}$} & \multicolumn{2}{|c|}{$\begin{array}{c}\text { Disease-Free } \\
\text { Survival }(n=48)\end{array}$} & \multicolumn{2}{|c|}{$\begin{array}{l}\text { Overall Survival } \\
\quad(n=77)\end{array}$} & \multicolumn{2}{|c|}{$\begin{array}{c}\text { Disease-Free } \\
\text { Survival }(n=71)\end{array}$} \\
\hline & Wilcoxon & Log Rank & Wilcoxon & Log Rank & Wilcoxon & Log Rank & Wilcoxon & Log Rank & Wilcoxon & Log Rank & Wilcoxon & Log Rank \\
\hline hTERT & 0.86 & 0.84 & 0.81 & 0.97 & 0.24 & 0.15 & 0.29 & 0.15 & 0.48 & 0.40 & 0.18 & 0.17 \\
\hline PCNA index & 0.012 & 0.0071 & 0.10 & 0.025 & 0.71 & 0.62 & 0.57 & 0.69 & 0.092 & 0.062 & 0.50 & 0.20 \\
\hline Stage & 0.0001 & 0.0001 & 0.0001 & 0.0001 & $* *$ & $* *$ & $* *$ & $* *$ & 0.0039 & 0.0028 & 0.034 & 0.011 \\
\hline Grade & 0.0004 & 0.0013 & 0.0016 & 0.0016 & 0.69 & 0.69 & 0.69 & 0.69 & 0.11 & 0.22 & 0.24 & 0.25 \\
\hline Pattern of growth & 0.0012 & 0.0094 & 0.0042 & 0.014 & $* *$ & $* *$ & $* *$ & $* *$ & 0.39 & 0.91 & 0.57 & 0.98 \\
\hline
\end{tabular}

PCNA, proliferating cell nuclear antigen index.

* $P$ value not detected because of one factor.

was barely detected in the normal urothelium of the upper urinary tract (in the few cases examined). This incidence accords well with the figure $(86 \%-$ 98\%) obtained for positive telomerase activity using the TRAP assay $(10-16)$, the figure $(88 \%)$ obtained for hTERC expression using RT-PCR (19), and that (91\%-100\%) obtained for hTERT expression using RT-PCR (17-19) in previously published studies of transitional cell carcinomas of the urinary bladder. Furthermore, it is well known that telomerase activity and hTERT expression are not present in most normal urothelia $(11,13,15,18)$. Several investigators have demonstrated a close relationship between hTERT expression and telomerase activity, indicating that transcription of hTERT may be involved in the mechanism underlying telomerase regulation (6). In contrast, hTERC was found to be expressed in the normal urothelium of the urinary bladder by Ito et al. (19), using RT-PCR, and in that of the upper urinary tract by us (22), using in situ hybridization. Furthermore, in the present study, we demonstrated a close relationship between hTERT scores and hTERC in TCC-UUT. Therefore, we support the idea put forward by Blasco et al. (7) that regulation of telomerase activity mainly by hTERT is detected only in late-stage tumors, whereas the hTERC level is up-regulated in the early preneoplastic stages.

Previous studies have reported a positive correlation between telomerase activity and both clinicopathologic findings and clinical outcome in neuroblastoma and gastric carcinomas $(4,5)$. Those authors suggested that cells expressing high levels of telomerase have a selective growth advantage because of the improved stability of chromosomes with restored telomeres. In TCC of the urinary tract, a relationship between telomerase activity and progression (as defined by stage and grade) has not been found in previous studies $(11,15,22)$. With regard to the relationship between hTERT expression and clinicopathologic findings in TCC of the bladder, only one report (dealing with 35 cases) has found that increases in pathologic grade and clinical stage correlated with an increased hTERT expression (assessed using RT-PCR) (17). In the present study, however, we did not find a significant correlation between hTERT expression and clinicopathologic findings (including grade and stage). The reason for this discrepancy is not clear, although the two studies differ in terms both of the number of cases investigated (35 cases versus 125 cases) and the method used (RT-PCR versus in situ hybridization).

It is generally accepted that telomerase activity is growth regulated and correlated with cell proliferation in normal human tissues, such as the endometrium during the menstrual cycle (24). In the present study, however, we did not find an association between hTERT expression and the PCNA index. Thus, future studies including a larger number of cases are needed to allow us properly to assess the relationship between the various telomerase RNA components and proliferative activity, clinicopathological findings, or clinical outcome in TCC-UUT.

Acknowledgment: The authors are indebted to Dr. R. Timms for correcting the English.

\section{REFERENCES}

1. Blackburn EH. Structure and function of telomeres. Nature 1991;350:569-73.

2. Counter CM, Avilion AA, LeFeuvre CE, Stewart NG, Greider CW, Harley CB, et al. Telomerase shortening associated with chromosome instability is arrested in immortal cells which express telomerase activity. EMBO J 1992;11:1921-9.

3. Kim NW, Piatyszek MA, Prowse KR, Harley CB, West MD, Ho PLC, et al. Specific association of human telomerase activity with immortal cells and cancer. Science 1994;266:2011-5.

4. Hiyama E, Hiyama K, Yokoyama T, Matsuura Y, Piatyszek MA, Shay JW. Correlating telomerase activity levels with human neuroblastoma outcomes. Nat Med 1995;1:249-55.

5. Hiyama E, Yokoyama T, Tatsumoto N, Hiyama K, Imamura $\mathrm{Y}$, Murakami Y, et al. Telomerase activity in gastric cancer. Cancer Res 1995;55:3258-62.

6. Nakamura TM, Morin GB, Chapman KB, Weinrich SL, Andrews WH, Linger J, et al. Telomerase catalytic subunit homologs from fission yeast and human. Science 1997;277: 955-9.

7. Blasco MA, Rizen M, Greider CW, Hanahan D. Differential regulation of telomerase activity and telomerase RNA during multi-stage tumorigenesis. Nat Genet 1996;12:200-4. 
8. Avilion AA, Piatyszek MA, Gupta J, Shay JW, Bacchetti S, Greider CW. Human telomerase RNA and telomerase activity in immortal cell lines and tumor tissues. Cancer Res 1996; 56:645-50.

9. Weinrich SL, Pruzan R, Ma L, Ouellette M, Tesmer VM, Holt $\mathrm{SE}$, et al. Reconstitution of human telomerase with the template RNA component hTR and the catalytic protein subunit hTRT. Nat Genet 1997;17:498-502.

10. Kamata S, Kageyama Y, Yonese J, Oshima H. Significant telomerase reduction in human superficial transitional cell carcinoma. Br J Urol 1996;78:704-8.

11. Kyo S, Kunimi K, Uchibayashi T, Namiki M, Inoue M. Telomerase activity in human urothelial tumors. Am J Clin Pathol 1997;107:555-60.

12. Yoshida K, Sugino T, Tahara H, Woodman A, Bolodeoku J, Nargund V, et al. Telomerase activity in bladder carcinoma and its implication for noninvasive diagnosis by detection of exfoliated cancer cells in urine. Cancer 1997;79:362-9.

13. Kinoshita H, Ogawa O, Kakehi Y, Mishina M, Mitsumori K, Itoh $\mathrm{N}$, et al. Detection of telomerase activity in exfoliated cells in urine from patients with bladder cancer. J Natl Cancer Inst 1997;89:724-30.

14. Linn JF, Lango M, Halachmi S, Schoenberg MP, Sidransky D. Microsatellite analysis and telomerase activity in archived tissue and urine samples of bladder cancer patients. Int J Cancer 1997;74:625-9.

15. Heine B, Hummel M, Müller M, Heicappell R, Miller K, Stein H. Non-radioactive measurement of telomerase activity in human bladder cancer, bladder washings, and in urine. J Pathol 1998;184:71-6.
16. Lee D-H, Yang S-C, Hong S-J, Chung B-H, Kim IY. Telomerase: a potential marker of bladder transitional cell carcinoma in bladder washes. Clin Cancer Res 1998;4:535-8.

17. De Kok JB, Schalken JA, Aalders TW, Ruers TJM, Willems HL, Swinkels DW. Quantitative measurement of telomerase reverse transcriptase (hTERT) mRNA in urothelial cell carcinomas. Int J Cancer 2000;87:217-20.

18. Suzuki T, Suzuki Y, Fujioka T. Expression of the catalytic subunit associated with telomerase gene in human urinary bladder cancer. J Urol 1999;162:2217-20.

19. Ito M, Kyo S, Kanaya T, Takakura M, Inoue M, Namiki M. Expression of human telomerase subunits and correlation with telomerase activity in urothelial cancer. Clin Cancer Res 1998;4:1603-8.

20. UICC (International Union Against Cancer). Renal pelvis and ureter. In: Sobin LH, Wittenkind C, editors. TNM classification of malignant tumours, 5th ed. New York: Wiley \& Sons, Inc.; 1997. pp. 183-6.

21. Murphy WM, Beckwith JB, Farrow GM. Tumors of the kidney, bladder, and related urinary structures. Atlas of tumor pathology. 3rd series, Fascicle 11. Washington, DC: Armed Forces Institute of Pathology; 1994. pp. 202-19.

22. Nakanishi K, Kawai T, Hiroi S, Kumaki F, Torikata C, Aurues $\mathrm{T}$, et al. Expression of telomerase mRNA component (hTR) in transitional cell carcinoma of the upper urinary tract. Cancer 1999;86:2109-16.

23. SAS technical report P-217, SAS/STAT software, the PHREG procedure, Version 6. Cary, NC: SAS Institute Inc.; 1991. p. 63.

24. Kyo S, Takakura M, Kohama T, Inoue M. Telomerase activity in human endometrium. Cancer Res 1997;57:610-4. 